\title{
Serological identification and molecular characterization of $B(A) 02$ subtype in patients and blood donors from Eastern China
}

\author{
Wen Wu, Yecui Zhang, Xingying Guo, Peng Wu, Zhibo Zhang*, Xiangyan Huang* \\ Department of Blood Transfusion, The General Hospital of Jinan Military Command, Jinan, Shandong 250031, China
}

\begin{abstract}
This study was designed to identify rare type ABO blood groups, B(A) 02, from Eastern China. Three samples with discordant serological results during routine blood type identification, and four samples from one sample family were selected. All of them were detected by serological method. The exon 6 and 7 of the ABO genes were amplified by PCR and sequenced. They were typed as AsubB by serology and as BO by genotype. In the AsubB samples, nt $700 \mathrm{C}>\mathrm{G}$ mutation was detected in the $\mathrm{B}$ gene, which was previously defined as $\mathrm{B}(\mathrm{A}) 02$ alleles. In these seven samples, six showed $\mathrm{B}(\mathrm{A}) 02 / \mathrm{O} 01$ and one showed $\mathrm{B}(\mathrm{A}) 02 / \mathrm{O} 02$. $\mathrm{B}(\mathrm{A}) 02$ allele was found to be more common in this study than $\mathrm{B}(\mathrm{A}) 04$, which is considered to be more frequent than $\mathrm{B}(\mathrm{A}) 02$. The careful identification of rare blood types is important for the safety of clinical blood transfusion.
\end{abstract}

Keywords: B(A)02, serological identification, molecular characterization, gene mutation, rare blood type

\section{INTRODUCTION}

The human blood grouping system is complicated by the presence or lack of antigens expressed on the red blood cell membrane. The ABO blood group is a major blood classification system, which is very important for transfusion safety and as the foundation of crossmatching blood between donors and recipients $^{[1,2]}$. The clinical significance of the ABO blood group system extends to a broader area beyond transfusion medicine and several reports have suggested an important involvement in the development of cardiovascular ${ }^{[3,4]}$, oncological ${ }^{[5]}$ and other diseases ${ }^{[6]}$. In addition to common $\mathrm{ABO}$ phenotypes, many $\mathrm{ABO}$ subgroups have been found to have a weak expression of the A or B antigen on red blood cells (RBCs), which makes blood typing difficult. The human ABO

*Correspondence to: Xiangyan Huang, PhD, Director of Department of Blood Transfusion, The General Hospital of Jinan Military Command, Jinan, Shandong 250031, China. Tel:86-531-51666968, Email:xiangyan73@aliyun.com; Zhibo Zhang, Department of Blood Trans- blood groups are controlled by alleles at a single gene locus on chromosome 9. The elucidation of gene sequence, common polymorphisms ${ }^{[7,8]}$, and genomic organization $^{[9,10]}$ of the $\mathrm{ABO}$ gene has opened another dimension that complements serological analysis by allowing determination of DNA sequence of alleles responsible for phenotypes observed ${ }^{[11,12]}$.

The phenotype $\mathrm{B}(\mathrm{A})$ was firstly discovered in 1985 , just after the anti-A BioClone (Ortho Diagnostic System) monoclonal antibody mixture was marketed, when it was found that anti-A reagent was reacting with RBCs that had previously been typed as $\mathrm{B}^{[13]}$. The $\mathrm{B}(\mathrm{A}) \mathrm{RBCs}$ are genetically categorized as group $\mathrm{B}$ and the serum of the individual contains anti-A reagent. The serum from A subgroup B individuals usually contain neither anti-A nor anti-B although they occasionally contain a weak anti-A, this difference allows discrimination of phenotypes of $\mathrm{B}(\mathrm{A})$. To date, six

fusion, The General Hospital of Jinan Military Command, Jinan, Shandong 250031, China. Tel:86-531-51666968, E-mail: zzb9063@sina.com. The authors reported no conflict of interests. 
$\mathrm{B}(\mathrm{A})$ alleles have been identified and characterized, and $\mathrm{B}(\mathrm{A}) 02$ is even more rare in China compared with $\mathrm{B}(\mathrm{A}) 04$. Individuals with the Cis AB phenotype are characterized by a non-classic mode of inheritance of $\mathrm{A}$ and $\mathrm{B}$ antigens expressed at the membrane of RBCs: $\mathrm{A}$ and $\mathrm{B}$ are not transmitted as two independent alleles but as a single allele, referred to as "CisAB" ${ }^{[14,15]}$. As rare types, $\mathrm{B}(\mathrm{A})$ and $\mathrm{Cis} \mathrm{AB}$ have similar performance in serological identification. The present study was designed to analyze the serological and molecular characteristics of $\mathrm{B}(\mathrm{A}) 02$.

\section{MATERIALS AND METHODS}

\section{Blood sample collection}

During the period from 2014 to 2016 , three samples with discordant serological results with AsubB were collected during routine blood type identification from all blood donors and patients in the General Hospital of Jinan Command, and then four samples from one sample' family were collected. The venous blood was selected from a healthy blood donor ZMM and hospital patients ZXL and WCZ with his family members.

The study was approved by the Institutional Review Board of the General Hospital of Jinan Military Command. Informed consent was voluntarily signed by each one before blood samples collection based on the full understanding of subjects on this study.

\section{Blood group serological typing}

ABO typing tests including RBC, serum blood grouping procedures, and the saliva substance test were carried out according to latest edition of the AABB Technical manual. Forward and reverse ABO phenotyping was conducted by agglutination testing at $4{ }^{\circ} \mathrm{C}$ and Room Temperature ${ }^{[16]}$. The tests were performed with commercial antisera according to the manufacturer's instructions by agglutination using murine monoclonal IgM: anti-A and anti-B (Shanghai Hemo-pharmaceutical\& Biological CO, Ltd.). The adsorption-elution studies with the patients' RBCs were carried out using human serum samples containing IgG anti-A and high-titer IgG anti-B, which were donated by Shanghai Red Cross Blood Center.

\section{Molecular analysis of ABO exons 6 and 7}

Genomic DNAs of 7 individuals with the $\mathrm{B}(\mathrm{A})$ phenotype were extracted from peripheral EDTAtreated anti-coagulated blood using a whole blood commercial kit (TIANamp Blood DNA Kit, Tiangen Biotech CO., LTD, Beijing, China). Real-Time PCR Assay was performed by ABI 7500 using the fluo-ABO subgroup genotyping kit (ABO subgroup in Chinese, Jiangsu LiBio Pharmaceutical Biotechnology Co., Ltd., China) based on SYBR Green, with the primers to detect the genotypes of $\mathrm{B}(\mathrm{A}) 02$, $\mathrm{B}(\mathrm{A}) 04$, cisAB01, and cisAB03. PCR with sequencespecific primers was performed for $\mathrm{ABO}$ blood group genotyping using two commercial kits (ABO basic; FluoGene, Inno-Train Diagnostik GmbH, Kronberg, Germany, and ABO genotyping kit; Jiangsu LiBio Pharmaceutical Biotechnology, China). The automatic software (FluoGene, technology transferred from the Germany INNO-Train Company, Jiangsu LiBio Pharmaceutical Biotechnology Co., Ltd.) was used to analyze the genotypes of A1, A2, B, O1, and $\mathrm{O} 2$ samples. Sequencing of 7 individuals was performed and sequence data were compared to $\mathrm{ABO}$ alleles listed in the RBC database ${ }^{[17]}$.

\section{RESULTS}

\section{Serological phenotype analysis}

Cases of B (A) phenotype were discovered as a result of discrepancies between forward and reverse typing in routine $\mathrm{ABO}$ grouping by the standard hemagglutination test. The RBCs of the samples were agglutinated by monoclonal and human anti-A and anti-B reagents. The serum samples contained middle-strong anti-A activity but no anti-B activity. The ABO phenotypes of W; Family members tested were shown in Fig.1. At the time of study, all the family members were healthy and had no history of hematologic disease. RBCS from the patient WCZ's mother (GEJ) were agglutinated by anti-A and anti-B reagent, suggesting that her serum samples contained low quantities of irregular anti-A. She was initially typed B(A). WCZ's father exhibited a classic Al type. The propositus (WCZ), her mother (GER), her sister (WAZ), her brother (WMQ), her son (MGM), and two individuals without consanguinity were typed as AsubB by serology (Table 1). The results from these

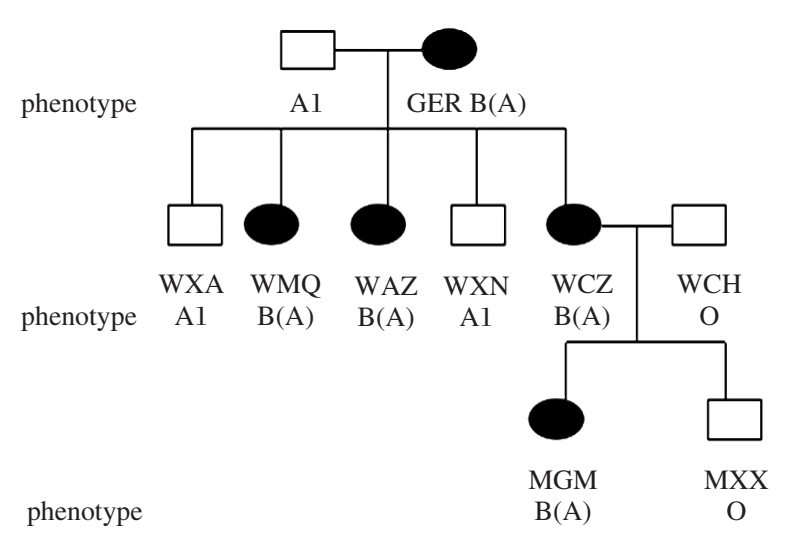

Fig.1 Schematic diagram of the inheritance of $B(A)$ in W. family. The phenotypes are indicated below each symbol. 
Table 1 Rare ABO phenotypes for the W. family and the unrelated individuals

\begin{tabular}{|c|c|c|c|c|c|c|c|c|c|c|}
\hline \multirow[b]{3}{*}{ Member } & \multicolumn{7}{|c|}{ Forward typing } & \multicolumn{3}{|c|}{ Reverse typing } \\
\hline & \multicolumn{3}{|c|}{ Anti-human regent } & \multicolumn{4}{|c|}{ Monoclonal regent } & \multirow[b]{2}{*}{$\mathrm{Bc}$} & \multirow[b]{2}{*}{ Oc } & \multirow[b]{2}{*}{ Selfc } \\
\hline & Anti-A & Anti-B & Anti-Al & Anti-B & Anti-H & Anti-AB & Ac & & & \\
\hline GER & $1+w$ & $3+$ & $2+s$ & $4+$ & $3+$ & $4+$ & $1+$ & 0 & 0 & 0 \\
\hline WCZ & $1+w$ & $2+$ & $2+\mathrm{s}$ & $3+$ & $3+$ & $4+$ & $1+$ & 0 & 0 & 0 \\
\hline WMQ & $1+w$ & $2+$ & $2+w$ & $3+$ & $3+$ & $4+$ & $2+$ & 0 & 0 & 0 \\
\hline WAZ & $1+w$ & $2+$ & $2+w$ & $3+$ & $3+$ & $4+$ & $2+$ & 0 & 0 & 0 \\
\hline MGM & $1+w$ & $2+$ & $2+s$ & $3+$ & $3+$ & $4+$ & $1+$ & 0 & 0 & 0 \\
\hline ZMM & $1+w$ & $3+$ & $2+s$ & $4+$ & $3+$ & $4+$ & $2+$ & 0 & 0 & 0 \\
\hline ZXL & $1+\mathrm{w}$ & $3+$ & $3+$ & $4+$ & $3+$ & $4+$ & $1+$ & 0 & 0 & 0 \\
\hline
\end{tabular}

w:week; s:strong

seven samples yielded the rare $\mathrm{ABO}$ phenotypes for AsubB.

\section{Sequencing and gene analysis}

To confirm the blood types of these samples, the genotypes of the W. Family, ZMM and ZXL were determined by amplification and direct sequencing of exon 6 and exon 7 of ABO. Commercial real-time PCR kit was used to detect $\mathrm{B}(\mathrm{A})$ DNA in sample from ZXL. The real-time PCR results confirmed $\mathrm{B}(\mathrm{A}) 02$ DNA in small volumes of blood with high concentrations in patient ZXL (Fig.2). When the consensus sequence of the A101 allele was compared with one haplotype of the sample, the O01 allele was determined in the samples from the W. Family and ZMM; the other haplotype of ZXL was identical to O02 allele, which included four mutations $(646 \mathrm{~T}>\mathrm{A} 681 \mathrm{G}>\mathrm{A}$ $771 \mathrm{C}>\mathrm{T} 829 \mathrm{G}>\mathrm{A}$ ) in exon 7 at the ABO locus. When these 7 haplotypes were compared to the B101 allele, nt700C $>\mathrm{G}$ mutations in exon 7 were found in all the haplotypes (Fig.3A and Fig.3B ), while another six mutations $(526 \mathrm{C}>\mathrm{G} 657 \mathrm{C}>\mathrm{T} 703 \mathrm{G}>\mathrm{A} \quad 796 \mathrm{C}>\mathrm{A}$ $803 \mathrm{G}>\mathrm{C} 930 \mathrm{G}>\mathrm{A}$ ) in exon 7 were found in the haplotypes of ZXL (Fig.3). Consequently, we could deduce

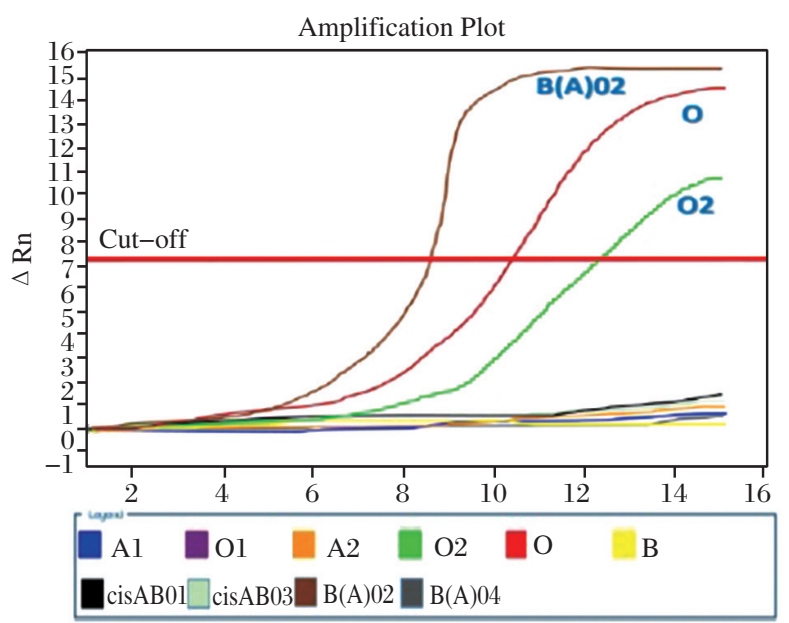

Fig 2 Results of Real-Time PCR Assay using the fluo-ABO subgroup genotyping kit based on SYBR Green for sample ZXL.
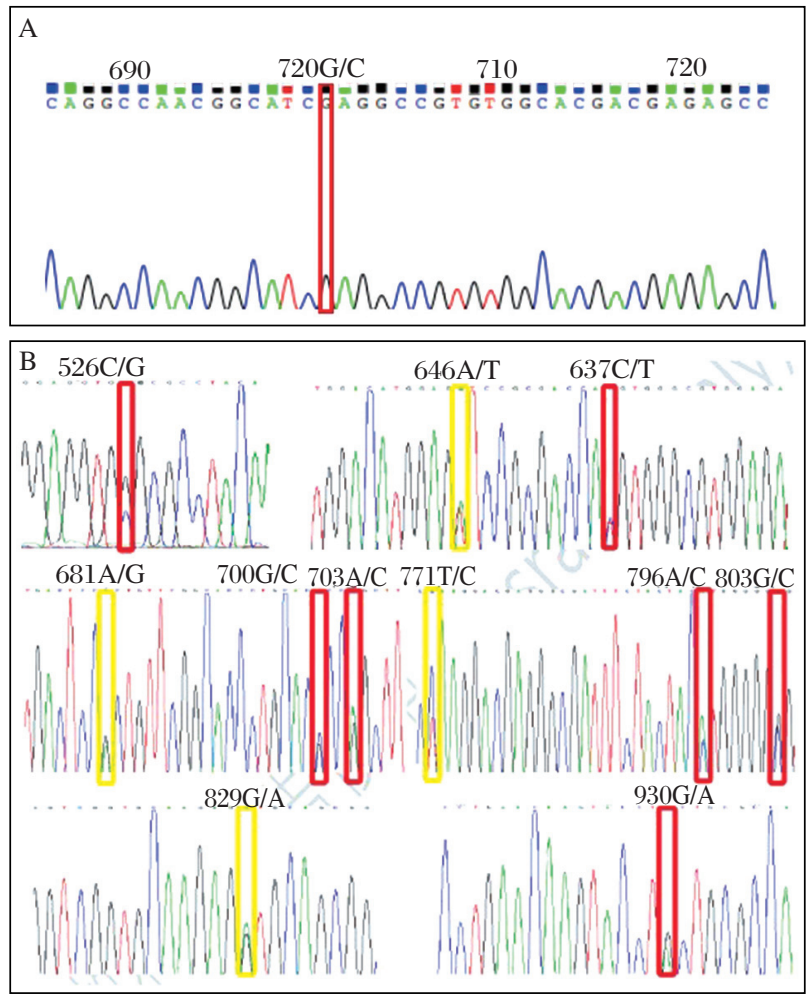

Fig 3 Mutations in exon 7 in the haplotypes of ZXL. A: The nt700C $>\mathrm{G}$ mutations in exon 7 were found in all the 7 haplotypes compared to the $\mathrm{B} 101$ allele. B: While another six mutations $(526 \mathrm{C}>\mathrm{G} 657 \mathrm{C}>\mathrm{T} 703 \mathrm{G}>\mathrm{A} \quad 796 \mathrm{C}>\mathrm{A} \quad 803 \mathrm{G}>\mathrm{C}$ $930 \mathrm{G}>\mathrm{A}$ ) were found in exon 7 in the haplotypes of $\mathrm{ZXL}$.

that the alleles from all samples were B101-like allele with a single nt $700 \mathrm{C}>\mathrm{G}$ or $526 \mathrm{C}>\mathrm{G} 657 \mathrm{C}>\mathrm{T} 700 \mathrm{C}>\mathrm{G}$ 703G $>$ A 796C $>$ A $803 \mathrm{G}>$ C 930G $>$ A mutations.

\section{DISCUSSION}

The frequency of $\mathrm{B}(\mathrm{A})$ allele in the Chinese population is very rare, especially the $\mathrm{B}(\mathrm{A}) 02$ in Eastern China. The frequency of $\mathrm{B}(\mathrm{A}) 04$ is usually significantly higher than that of $\mathrm{B}(\mathrm{A}) 02$ in China. According to the literature report, six rare alleles were researched in China from 1,716,442 non-repeat donors, which included cisAB alleles, cis-AB01, cis-AB02, cis- 
$\mathrm{AB} 02, \mathrm{~B}(\mathrm{~A}) 02, \mathrm{~B}(\mathrm{~A}) 04$, and $\mathrm{B}(\mathrm{A}) 06$. The frequency of $\mathrm{B}(\mathrm{A}) 04$ was higher $(1.6 / 100,000)$ than $\mathrm{B}(\mathrm{A}) 02$ $(0.78 / 100,000)$ and cis-AB01 $(0.66 / 100,000)^{[18]}$. Interestingly, the results in the present study showed that the frequency of $\mathrm{B}(\mathrm{A}) 02$ in Eastern China was significantly higher than $\mathrm{B}(\mathrm{A}) 04$, which differed from previous reports. A total of 54,305 samples were typed during the study period, 3 cases of $\mathrm{B}(\mathrm{A}) 02$ allele were identified with high frequency $(5.52 / 100,000)$. Another four cases of B(A) 02 allele belonged to one patient's family. The phenotype in the family compatible with B(A) was transmitted from the mother to five of her children and grandson. To confirm this hypothesis, we insisted that a final analysis conclusion was needed to explore the influence of geographical differences. The high frequency of $\mathrm{B}(\mathrm{A}) 02$ may be related to gene diversity in the Chinese population in different areas, and the limited the number of samples in this study. A more accurate conclusion can be reached when more population groups are screened.

The data regarding the prevalence of different blood group antigens in any given population is always helpful in management of transfusion ${ }^{[19,20]}$. B(A) and Cis $A B$ showed $A B$ blood type in routine serological forward group test, and similar results like "anti-H $3+--4+$, anti-A 1+--2+, anti-B-" in reverse group tests. The auto antibodies were negative for samples with $\mathrm{B}(\mathrm{A})$ and $\mathrm{Cis} \mathrm{AB}$. It is difficult to identify $\mathrm{B}(\mathrm{A})$ and $\mathrm{Cis} \mathrm{AB}$ by serological methods. The sequencing of the ABO alleles provides the molecular basis of distinguishing subtype. Such knowledge is, in turn, helpful in revealing the effect of certain amino acid variations on the serological specificity or the activity of glycosyltransferase. Sequencing analysis found that seven samples were typed as BO by genotype even though they were typed as AsubB by serology methods. Point mutation was detected in 7 samples of the $B$ gene with $700 \mathrm{C}>\mathrm{G}$ mutation, which was previously defined as B(A)02 alleles. Nt700 mutation could result in amino acid change at amino acid 234 position. Obviously, mutations at the amino acid 234 position are most probably capable of altering the specificity of the ABO enzyme. Six B(A)02 have a single nucleotide deletion, G261, in exon 6 typed as B(A) 02/ $\mathrm{O} 01$, and the other $\mathrm{B}(\mathrm{A}) 02$ has nucleotide deletion on 681,771,829, and G261 in exon 6 typed as B(A) 02/ $\mathrm{O} 02$.

The $A B O$ gene that encodes the glycosyltransferases and is responsible for the conversion of $\mathrm{H}$ substance to blood group A and B antigens is located on chromosome $9^{[21]}$. It consists of seven exons ranging in size from 28 to $688 \mathrm{bp}^{[22]}$. The last two exons (exons 6 and 7), comprising $823 \mathrm{bp}$ of the transcribed 1,062 bp
mRNA, encode for the catalytic domain of the $\mathrm{ABO}$ glycosyltransferases ${ }^{[23,24]}$. Theoretically, there are eight enzymes (AAA, AAB, ABA,BAA, ABB, BAB, $\mathrm{BBA}, \mathrm{BBB}$ types) that have been characterized with interchanges in the last three of the four amino acids, including AAAA (Arg-176, Gly-235, Leu-266, and Gly-268) or BBBB (Gly-176, Ser-235, Met266, and Ala-268). Until now, nine $\mathrm{B}(\mathrm{A})$ or cis $\mathrm{AB}$ alleles, including five $\mathrm{B}(\mathrm{A})$ alleles and four cis $\mathrm{AB}$ alleles ${ }^{[25,26]}$, have been identified and characterized. $\mathrm{ABO} * \mathrm{~B}(\mathrm{~A}) 01$ was typed as $\mathrm{BABB}, \mathrm{B}(\mathrm{A}) 03$ was typed as $\mathrm{BABB}$ with nt $657 \mathrm{C}>\mathrm{T}$, and $\mathrm{B}(\mathrm{A}) 04$ was typed as $\mathrm{BBBB}$ with nt $640 \mathrm{~A}>\mathrm{G}^{[27,28]}$. B(A)02 was typed as $\mathrm{BBBB}$ with nt $700 \mathrm{C}>\mathrm{G}^{[29,30]}$. B(A)02 defined by $\mathrm{Yu}$ et al in Taiwan ${ }^{[31]}$, had a single substitution in exon 7 for B101 at codon 234, but the proline was replaced by an alanine. Unlike the hydroxyl group-containing polar serine, the nonpolar alanine results in decreased B transferase activity and very low A transferase activity. These previous studies demonstrated the genetic heterogeneity of these subgroups. In these seven samples, six showed $\mathrm{B}(\mathrm{A}) 02 / \mathrm{O} 01$ and one showed $\mathrm{B}(\mathrm{A}) 02 / \mathrm{O} 02$, which were type as BBBB.

Under the consistency of cross matching, it is safe and effective to infuse $\mathrm{RBCs}$ from $\mathrm{B}(\mathrm{A})$ donor to type $B$ receptor. When $B(A)$ blood of donor was infused to type $\mathrm{B}$ receptor, $\mathrm{Hb}$ rising conformed to the expected value and no hemolytic reaction occurred in the receptor. What is worth paying attention to is how to select the blood for B (A) receptor for clinical transfusion. The $\mathrm{B}(\mathrm{A})$ allele blood receptor should be transfused with blood type B or O RBCs and autologous transfusion is recommended.

In conclusion, this study reveals that $\mathrm{B}(\mathrm{A}) 02$ was found with relative high prevalence in the donors and patients from Eastern China, although a significantly higher frequency of $\mathrm{B}(\mathrm{A}) 04$ than $\mathrm{B}(\mathrm{A}) 02$ were reported before in China. Sequencing and gene analysis are helpful for identifying rare types. The genetic essence of rare blood groups and clinical blood transfusion for rare blood groups are worthy of further study.

\section{Acknowledgments}

We deeply thank the assistance of The General Hospital of Jinan Military Command in collecting blood samples and sequencing in Shanghai Blood Center and Jiangsu LiBio Pharmaceutical Biotechnology Co., Ltd.. This work was supported by Grant No.2014BS07 and No.2016ZD05 from the The General Hospital of Jinan Military Command Foundation.

\section{References}

[1] Cooling L. Blood groups in infection and host suscepti- 
bility. Clin Microbiol Rev, 2015; 28(3): 801-70.

[2] Vitiazeva V, Kattla JJ, Sarah A, et al. The O-Linked glycome and blood group antigens ABO on mucintype glycoproteins in mucinous and serous epithelial ovarian tumors. PLoS One, 2015; 10(6):1-20.

[3] Franchini M, Liumbruno GM, Lippi G. The prognostic value of $\mathrm{ABO}$ blood group in cancer patients. Blood Transfus, 2016; 14(5):434-40.

[4] He M, Wolpin B, Rexrode K, et al. ABO blood group and risk of coronary heart disease in two prospective cohort studies. Arterioscler Thromb Vasc Biol, 2012; 32(9):2314-20.

[5] Risch HA, Lu L, Wang J, et al. ABO blood group and risk of pancreatic cancer: A study in Shanghai and metaAnalysis. Am J Epidemiol, 2013; 177(12):1326-37.

[6] Jukic I, Bingulac-Popovic J, Dogic V, et al. Evaluation of $\mathrm{ABO}$ blood groups as a risk factor for myocardial infarction. Blood Transfus, 2012; 29(10):1-2.

[7] Clausen H, White T, Takio K, et al. Isolation to homogeneity and partial characterization of a histo-blood group A defined Fucal 2 Galal 3- Nacetylgalactosaminyl transferase from human lung tissue. J Biol Chem, 1990; 265(27):1139-45.

[8] Yamamoto F, McNeill PD, Hakomori S. Genomic organization of human histo-blood group ABO genes. Glycobiology, 1995; 5(5):51-8.

[9] Bennett EP, Steffensen R, Clausen H, et al. Genomic cloning of the human histo-blood group ABO locus. Biochem Biophys Res Commun,1995; 206(1):318-25.

[10] Chester MA, Olsson ML. The ABO blood group gene: a locus of considerable genetic diversity. Transfus Med Rev, 2001; 15(3):177-200.

[11] Patnaik SK, Helmberg W, Blumenfeld OO. BGMUT: NCBI dbRBC database of allelic variations of genesencoding antigens of blood group systems. Nucleic Acids Res, 2012; 40(2):1023-9.

[12] He M, Wolpin B, Rexrode K, et al. ABO blood group and risk of coronary heart disease in two prospective cohort studies. Arterioscler Thromb Vasc Biol, 2012; 32(9):2314-20.

[13] Yamamoto F, Clausen H, White T, et al. Molecular genetic basis of the histo-blood group ABO system. $\mathrm{Na}-$ ture, 1990; 345(17):229-33.

[14] Yoon J, Youk HJ, Chang JH, et al. Identification of the $\mathrm{ABO} *$ cis-AB04 allele with a unique substitution C796A: the first case in Korea. Ann Lab Med, 2016; 36(6):620-2.

[15] Huang Y, Lin J, Zhu S. Genetic sequencing analysis of A307 subgroup of ABO blood group. Med Sci Monit, 2015; 21(9):2781-5.

[16] Kang SJ, Lim YA, Baik SY. Comparison of ABO antibody titers on the basis of the antibody detection method used. Ann Lab Med, 2014; 34(4):300-6.

[17] Blumenfeld OO, Patnaik SK. Allelic genes of blood group antigens: a source of human mutations and cSNPs documented in the blood group antigen gene mutation database. Hum Mutat, 2004; 23(1):8-16.

[18] Jin S, Cai X, Liu X, et al. Study on cisAB and B(A) subgroups in Shanghai blood donors. Chinese Journal of Blood Transfusion(in Chinese), 2013; 26(12): 1198201.

[19] Canellini G, Rubin O, Delobel J, et al. Red blood cell microparticles and blood group antigens: an analysis by flow cytometry. Blood Transfus, 2012; 10(2):39-45.

[20] Tomlinson JE, Taberner E, Boston RC, et al. Survival time of cross-match incompatible red blood cells in adult horses. J Vet Intern Med, 2015; 29(6):1683-8.

[21] Muthana SM, Gulley JL, Hodge JW, et al. ABO blood type correlates with survival on prostate cancer vaccine therapy. Oncotarget, 2015; 6(31):32244-56.

[22] Bugert P, Rink G, Kemp K. Blood Group ABO Genotyping in Paternity Testing. Transfus Med Hemother, 2012; 39(3):182-6.

[23] Beck ML, Yates AD, Hard man J. Identification of a sub set of group B donors reactive with monoclonal anti -A reagent. Am J Clin Pathol, 1989; 92(5):625-9.

[24] Watkins WM. Molecular basis of antigenic specificity in the $\mathrm{ABO}, \mathrm{H}$ and Lewis blood group systems. Glycoproteins, 1995(5):313-90.

[25] Cohen M, Hurtado-Ziola N, Varki A. ABO blood group glycans modulate sialic acid recognition on erythrocytes. Blood, 2009; 114(17):3668-76.

[26] EL-Zawahri MM, Luqmani YA. Molecular genotyping and frequencies of $\mathrm{A} 1, \mathrm{~A} 2, \mathrm{~B}, \mathrm{O} 1$ and $\mathrm{O} 2$ alleles of the ABO blood group system in a Kuwaiti population. Int $J$ Hematol, 2008; 87(3):303-9.

[27] Yamamoto F, Marken J, Tsuji T, et al. Cloning and characterization of DNA complementary to human UDP-GalNac: fucal2 GalNac transferse mRNA. J Biol Chem,256(2):1146-51.

[28] Mifsud NA, Watt JM, Condon JA, et al. A novelcis$\mathrm{AB}$ variant allele arising from a nucleotide substitution A796C in the B transferase gene. Transfusion, 2000; 40(10):1276-7.

[29] Daniels G. Blood groups: the past 50 years. Transfusion, 2010; 50(2):281- 9 .

[30] Seltsam A, Hallensleben M, Kollmann A, et al. Systematic analysis of the $\mathrm{ABO}$ gene diversity within Exon 6 and Exon 7 by PCR screening reveals new ABO alleles. Transfusion, 2003; 43(4):428-39.

[31] Yu LC, Lee HL, Chan YS, et al. The molecular basis for the $\mathrm{B}(\mathrm{A})$ allele: an amino acid alteration in the human histoblood group B a-(1,3)-galactosyltransferase increases its intrinsic a-(1,3)-N-acetylgalactosamyltransferase activity. Biochem Biophys Res Commun, 1999; 262(2):487-93.

(Received 18 Juanary 2017, Revised 23 February 2017, Accepted 28 February 2017) 